\title{
BIOLOGICAL PROPERTIES OF AUREOBASIDIN A, A CYCLIC DEPSIPEPTIDE ANTIFUNGAL ANTIBIOTIC ${ }^{\dagger}$
}

\author{
Kazutoh Takesako, ${ }^{*}$ Hirovuki Kuroda, Toshiaki Inoue, Fumiyo Haruna, \\ YoshIE YoshIKAWA and IKUNOSHIN Kato \\ Biotechnology Research Laboratories, Takara Shuzo Co., Ltd., \\ 3-4-1 Seta, Otsu, Shiga 520-21, Japan \\ Katsuhisa Uchida, Tamio HiRatani and Hideyo Yamaguchi \\ Research Center for Medical Mycology, Teikyo University School of Medicine, \\ 359 Otsuka, Hachioji, Tokyo 192-03, Japan
}

(Received for publication May 20, 1993)

\begin{abstract}
Aureobasidin A (AbA) is a novel cyclic depsipeptide antifungal antibiotic. The antifungal activity of $\mathrm{AbA}$ was studied in vitro and in vivo in comparison with clinically effective antifungal agents, amphotericin $\mathrm{B}$ and fluconazole. AbA was highly active in vitro against many pathogenic fungi, including Candida albicans, Cryptococcus neoformans, Blastomyces dermatitidis and Histoplasma capsulatum. The activity was superior to amphotericin B in most cases. AbA exhibited fungicidal action toward growing cultures of $C$. albicans. It was highly tolerated by mice and showed good efficacy in the treatment of murine systemic candidiasis when given orally or subcutaneously. AbA's fungicidal action in mice with candidiasis was more effective than fluconazole and amphotericin B.
\end{abstract}

The incidence of systemic fungal infections are increasing in immune compromised patients with several underlying diseases, such as leukemia and acquired immunodeficiency syndrome (AIDS), and in patients receiving anti-neoplastic agents, immunosuppressive agents or broad spectrum antibacterial antibiotics. Amphotericin B, flucytosine, and two imidazole drugs, miconazole and ketoconazole, have been the drugs of choice for systemic antifungal chemotherapy. Recently, two new oral triazoles, fluconazole and itraconazole, ${ }^{11}$ have been successfully developed and are now available for the treatment of some systemic fungal infections. However, clinical usefulness of all of these drugs is limited to insufficient therapeutic efficacy and/or toxicity. Thus there is a need for novel antifungal agents with a greater clinical efficacy.

Aureobasidin A (AbA) is a new antifungal cyclic depsipeptide antibiotic (Fig. 1) produced by Aureobasidium pullulans $\left.\mathrm{R} 106 .{ }^{2} 4\right)$ The characteristic of the structure of AbA is that of a peptide composed of eight L-form amino acids linked through one hydroxy acid to form a ring structure. There are some cyclic peptide antibiotics with antifungal activity in vitro, including valinomycin, ${ }^{5)}$ syringomycin, ${ }^{6,7)}$ calophycin $^{8)}$ and aculeacin/echinocandin family. ${ }^{9 \sim 11)}$ Many of them effect cell membrane permeability and have toxicity to eukaryotic cells. Several antifungal cyclic peptides with a long-chain fatty acid, such as aculeacin A, echinocandin B and their analogs, inhibit fungal cell wall synthesis with low acute toxicity ${ }^{9}{ }^{90}$ However, they show a narrow spectrum antifungal activity, ineffectiveness to murine candidiasis when given orally, and hemolytic effect. On the other hand, $\mathrm{AbA}$ has a broader spectrum and higher

$\dagger$ Presented in part as a poster at the 30th ICAAC (Atlanta, GA, U.S.A. October 21 24, 1990); Program and Abstracts No. 593. 
Fig. 1. Structure of aureobasidin A.

Abbreviations: D-Hmp, $(2 R, 3 R)$-2-hydroxy-3-methylpentanoic acid; L-MeVal, L- $N$-methylvaline; L-MePhe, L- $N$-methylphenylalanine; L- $\beta$ HOMeVal, L- $\beta$-hydroxy- $N$-methylvaline.

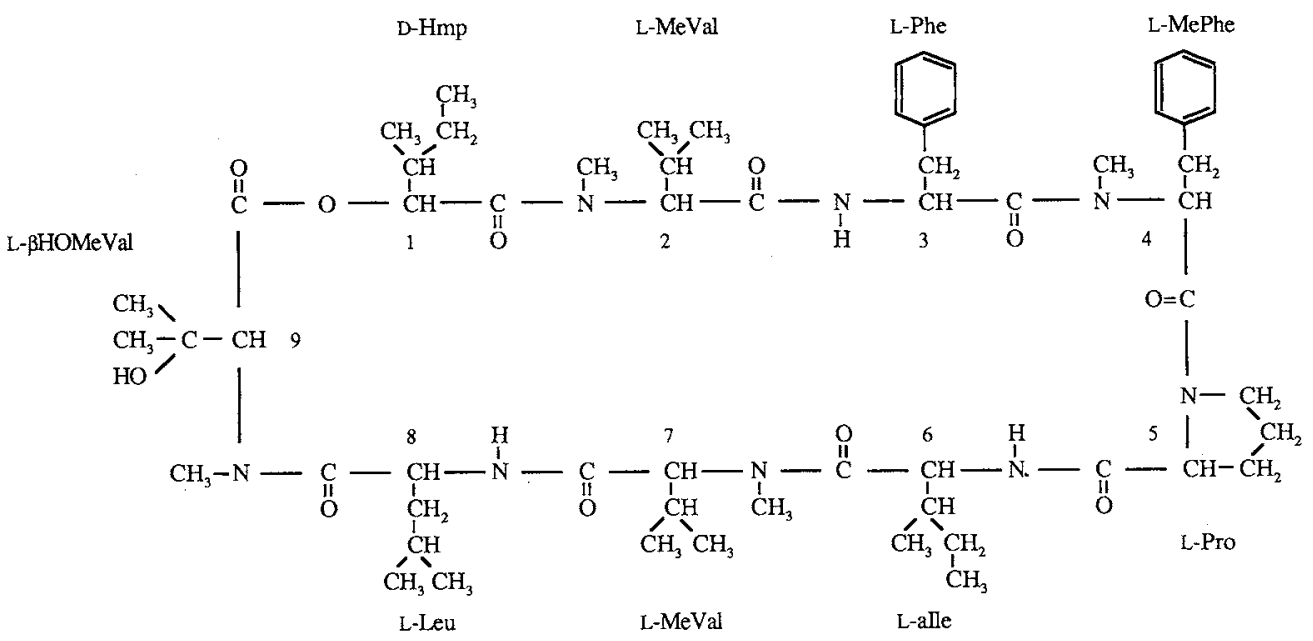

effectiveness to murine candidiasis than aculeacin/echinocandins. ${ }^{2)}$ In this paper, we describe the results of studies on the biological properties of AbA with special reference of its in vitro activity against a wide range of medically important fungi, therapeutic efficacy in murine systemic candidiasis, and acute toxicity toward mice.

\section{Materials and Methods}

Chemicals

Amphotericin B (Fungizone) and fluconazole (Diflucan) were purchased from Squibb Japan Inc. and Pfizer Pharmaceuticals Inc., respectively. AbA was prepared as described in the preceding paper. ${ }^{3)}$ Amphotericin B and fluconazole were dissolved in sterile water and diluted with sterile physiological saline to give a required concentration. AbA was dissolved in a mixture of Tween $80-\mathrm{EtOH}$ - saline $(1: 9: 40$, $\mathrm{v} / \mathrm{v})$ at a concentration of $10 \mathrm{mg} / \mathrm{ml}$, and diluted with Tween $80-\mathrm{EtOH}(1: 9)$ for in vitro studies and with saline in vivo studies to give a required concentration.

\section{In Vitro Antimicrobial Activity}

The minimum growth-inhibitory concentrations (MICs) for fungi and bacteria were determined by the agar dilution method using Casitone agar (glucose $2 \%$, Difco Casitone $0.9 \%$, yeast extract $1 \%$, $\mathrm{KH}_{2} \mathrm{PO}_{4} 0.1 \%, \mathrm{NaH}_{2} \mathrm{PO}_{4} 0.1 \%$, sodium citrate $1 \%$, agar $2 \%$, w/v) and heart infusion bouillon agar, respectively. A loopful of a suspension of a microorganism containing approximately $5 \times 10^{7} \mathrm{cells} / \mathrm{ml}$ was streaked on the surface of the agar plates containing graded concentrations of the drugs. After incubation at 27 or $37^{\circ} \mathrm{C}$ for 4 or 7 days, the lowest concentration of the drug virtually attaining complete inhibition of fungal growth was defined as MIC.

\section{Fungicidal Activity}

A loopful of a slant culture of C. albicans TIMM 1768 was inoculated into a L-shaped tube containing $10 \mathrm{ml}$ of YNBG broth (Difco yeast nitrogen base $0.67 \%$, glucose $2 \%, \mathrm{v} / \mathrm{v}$ ). The inoculated tubes were incubated at $37^{\circ} \mathrm{C}$ overnight. Cells were harvested by centrifugation and suspended in fresh YNBG broth or sterile saline so as to contain approximately $1 \times 10^{6} \mathrm{cells} / \mathrm{ml}$. A $9.9-\mathrm{ml}$ portion of the cell suspension was dispensed into each $\mathrm{L}$-shaped tube which received $100 \mu \mathrm{l}$ of an AbA solution or solvent. All of the tubes were incubated at $37^{\circ} \mathrm{C}$ with shaking for 24 hours. At intervals, from the incubation mixture, an 
aliquot was removed for microscopic observation of morphological changes, and a $200-\mu 1$ portion was sampled for viable cell count by a conventional plating method on Sabouraud-dextrose (SD) agar plates containing $100 \mu \mathrm{g} / \mathrm{ml}$ ampicillin (Sigma).

\section{In Vivo Antifungal Activity against Candidiasis}

Therapeutic efficacy of $\mathrm{AbA}$ was examined in comparison with amphotericin $\mathrm{B}$ and fluconazole in the murine model of systemic candidiasis. C. albicans TIMM 1768 was grown at $37^{\circ} \mathrm{C}$ for 18 hours in a L-shaped tube containing SD broth. Cells were harvested by centrifugation and suspended in sterile saline to give a final concentration of $1 \times 10^{7} \mathrm{cells} / \mathrm{ml}$. ICR mice (female, 5 weeks old, weighing $20 \sim 24 \mathrm{~g}$ ) were infected by iv injection of $0.1 \mathrm{ml}$-volume (per mouse) of the cell suspension via a tail vein. Groups of five infected mice were treated by sc, iv or po administration of the testing drugs at dosages of $2.5,5,10,20$, 40 or $80 \mathrm{mg} / \mathrm{kg}$ for $\mathrm{AbA} ; 0.63,2.5,10,20,40$ or $80 \mathrm{mg} / \mathrm{kg}$ for fluconazole; and $0.16,0.63,1.25,2.5$ or $5 \mathrm{mg} / \mathrm{kg}$ for amphotericin B. Mice were treated with the drugs once daily for 6 days from day- 0 ( 4 hours after infection) to -5 or from day-5 to -9 .

\section{Culture Study of the Kidneys from C. albicans-infected Mice}

Groups of mice were infected as described above and treated with AbA, fluconazole or amphotericin B. AbA or fluconazole was administered orally once daily from day- 0 to -6 at the dose of $20 \mathrm{mg} / \mathrm{kg}$ and from day-3 to -9 at the dose of $40 \mathrm{mg} / \mathrm{kg}$. Amphotericin B was given subcutaneously once daily from day-3 to -9 at the dose of $5 \mathrm{mg} / \mathrm{kg}$. On day -0 and $-4,-7,-10,-14$, and -21 after infection, some mice in each group were sacrificed and their kidneys were removed aseptically. The removed kidneys were sectioned through the middle and the exposed surface was stamped on SD agar plates for inoculation. All of the plates were incubated at $30^{\circ} \mathrm{C}$ for 2 days and the number of visibly growing colonies of $C$. albicans were counted. When five or fewer colonies per specimen were grown, it was assumed that mycological cure was achieved.

\section{Toxicological Study}

AbA was dissolved in a mixture of Tween 80 - EtOH - PEG $400(1: 9: 90, \mathrm{v} / \mathrm{v})$ at concentrations of 10 to $50 \mathrm{mg} / \mathrm{ml}$. A single dose was administered to groups of five female ICR mice by the iv, ip, sc and po routes. The mice were observed daily for 7 days for physical and behavioral signs of toxicity.

\section{Results and Discussion}

The MICs of AbA and amphotericin B against a wide range of medically important fungi are shown in Table 1. AbA exhibited a broad antifungal spectrum, inhibiting almost all species of pathogenic yeasts, dematiaceous fungi and dimorphic fungi, as well as some of aspergilli. AbA was highly active against causative agents of several deep-seated mycoses, namely Candida spp., Cryptococcus neoformans, Histoplasma capsulatum and Blastomyces dermatitidis at concentrations lower than $0.63 \mu \mathrm{g} / \mathrm{ml}$, and those of chromomycosis dematiaceous fungi at $\leq 2.5 \mu \mathrm{g} / \mathrm{ml}$. The activities of AbA were greater than those of amphotericin B on a weight basis. C. albicans and all other Candida spp. were most susceptible to AbA; all strains tested were inhibited by the drug at concentrations $0.08 \mu \mathrm{g} / \mathrm{ml}$ or lower, which were more than ten times lower than the MICs of amphotericin B. Some species or strains of aspergilli were also sensitive to AbA, but others, including most medically important species, Aspergillus fumigatus, A. niger and A. flavus, were only weakly or slightly sensitive. Dermatophytes were relatively insensitive to AbA. On the other hand, the growth of the bacteria tested, including Staphylococcus aureus and Escherichia coli, was not affected by AbA.

$\mathrm{AbA}$ exerted fungicidal action toward growing culture of $C$. albicans even at concentrations near the MIC, but it hardly affected the viability of non-growing cells of this yeast (Fig. 2). These results suggest 
Table 1. Antifungal spectrum of aureobasidin $\mathrm{A}(\mathrm{AbA})$ and amphotericin $\mathrm{B}$.

\begin{tabular}{|c|c|c|c|}
\hline \multirow{2}{*}{ Strain } & \multirow{2}{*}{ TIMM No. } & \multicolumn{2}{|c|}{$\mathrm{MIC}(\mu \mathrm{g} / \mathrm{ml})$} \\
\hline & & $\mathrm{AbA}$ & Amphotericin B \\
\hline Candida albicans & 0144 & $<0.04$ & 2.5 \\
\hline C. albicans & 1529 & $<0.04$ & 2.5 \\
\hline C. albicans & 1623 & $<0.04$ & 2.5 \\
\hline C. albicans var. stellatoidea & 1308 & $<0.04$ & 0.63 \\
\hline C. tropicalis & 0312 & 0.08 & 2.5 \\
\hline C. tropicalis & 0315 & 0.08 & 2.5 \\
\hline C. kefyr & 0298 & 0.16 & 2.5 \\
\hline C. parapsilosis & 0287 & 0.16 & 5 \\
\hline C. krusei & 0270 & $<0.04$ & 2.5 \\
\hline C. guilliermondii & 0257 & 0.08 & 1.25 \\
\hline C. glabrata & 1062 & $<0.04$ & 2.5 \\
\hline C. glabrata & 1064 & 0.08 & 2.5 \\
\hline Cryptococcus neoformans & 0354 & 0.63 & 2.5 \\
\hline Cr. neoformans & 0355 & 0.31 & 2.5 \\
\hline Cr. neoformans & 0363 & 0.31 & 2.5 \\
\hline Cr. terreus & 0424 & 0.31 & 2.5 \\
\hline Rhodotorula rubra & 0923 & 0.63 & 10 \\
\hline Aspergillus fumigatus & 0063 & 20 & 5 \\
\hline A. fumigatus & 0068 & $>80$ & 5 \\
\hline A. clavatus & 0056 & 0.16 & 2.5 \\
\hline A. flavus & 0058 & $>80$ & 20 \\
\hline A. nidulans & 0112 & 0.16 & 10 \\
\hline A. niger & 0113 & $>80$ & 5 \\
\hline A. terreus & 0120 & 5 & 80 \\
\hline Penicillium citrinum & 1330 & $>80$ & 10 \\
\hline P. commune & 1331 & 1.25 & 20 \\
\hline P. crustorum & 1332 & $>80$ & 20 \\
\hline Trichophyton mentagrophytes & 1189 & 10 & 5 \\
\hline T. mentagrophytes & 1196 & $>80$ & 5 \\
\hline T. rubrum & 1216 & $>80$ & 1.25 \\
\hline Microsporum canis & 0760 & $>80$ & 20 \\
\hline Epidermophyton floccostum & 0431 & 2.5 & 2.5 \\
\hline Fonsecaea pedrosoi & 0482 & 0.31 & 5 \\
\hline Phialophora verrucosa & 0903 & $>80$ & 20 \\
\hline Exophiala werneckii & 1334 & 1.25 & 10 \\
\hline Cladosporium bantianum & 0343 & 0.63 & 10 \\
\hline Cl. carrionii & 0337 & 1.25 & 10 \\
\hline Sporothrix schenckii & 0959 & $>80$ & 5 \\
\hline Histoplasma capsulatum & 0713 & 0.16 & 2.5 \\
\hline H. capsulatum & 0714 & 0.08 & 5 \\
\hline Paracoccidioides brasiliensis & 0880 & 0.31 & 2.5 \\
\hline Geotrichum candidum & 0694 & 0.63 & 20 \\
\hline Blastomyces dermatitidis & 1690 & $<0.04$ & 0.31 \\
\hline B. dermatitidis & 0126 & 0.31 & 2.5 \\
\hline
\end{tabular}

that $\mathrm{AbA}$ does not damage the cell membrane permeability and may have an effect similar to aculeacin/echinocandins, which inhibit fungal cell wall $\beta$-1,3-glucan synthesis. ${ }^{11.12)}$ However, AbA differed from these antibiotics in antimicrobial spectrum (Table 1) and in their effect on morphological changes. ${ }^{13)}$ $\mathrm{AbA}$ has no fatty acid moiety which is present in aculeacin and echinocandins. The fatty acid moiety was thought to be responsible for the activity of these antibiotics. ${ }^{14)}$ Thus AbA may have another mode of action, although the target for the AbA activity remains to be answered. 
Fig. 2. Effect of aureobasidin A (AbA) on the viability of C. albicans.

Cells were grown in YNBG broth (a) or incubated in saline (b) containing AbA at the concentrations of none $(\times), 0.025(\bigcirc), 0.10(\bullet), 0.39(\square), 1.56(\square), 6.25(\triangle)$ and $25 \mu \mathrm{g} / \mathrm{ml}(\Delta)$.

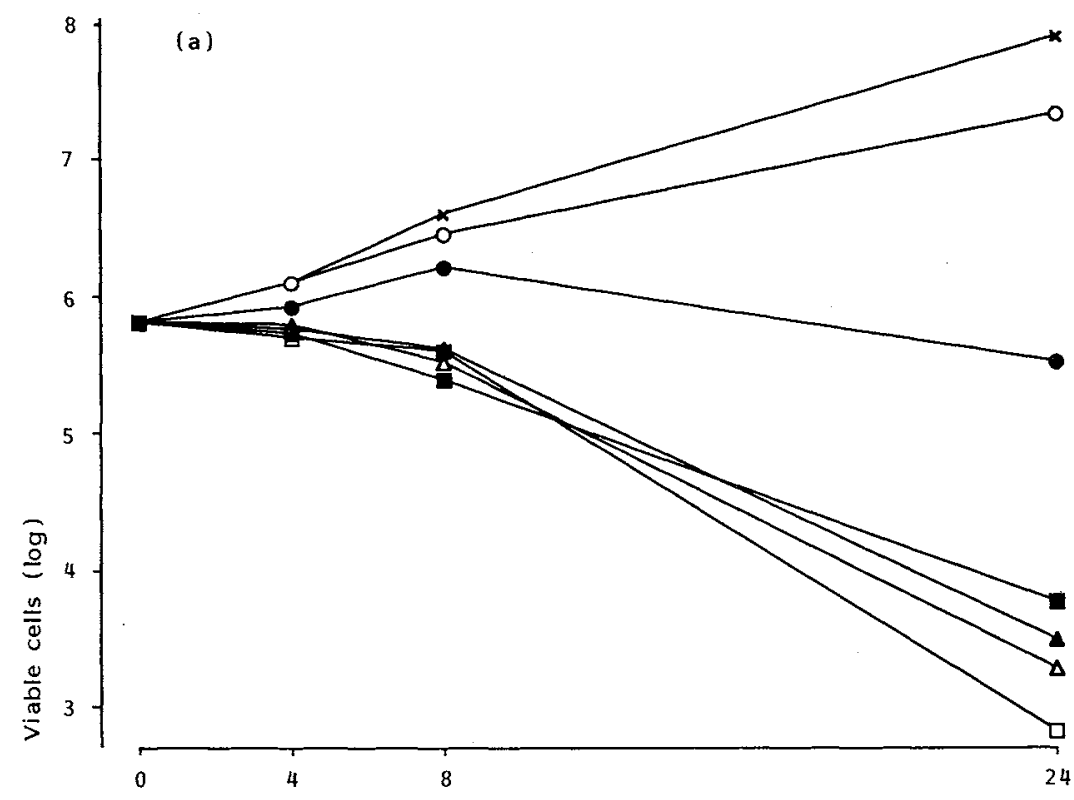

( b)

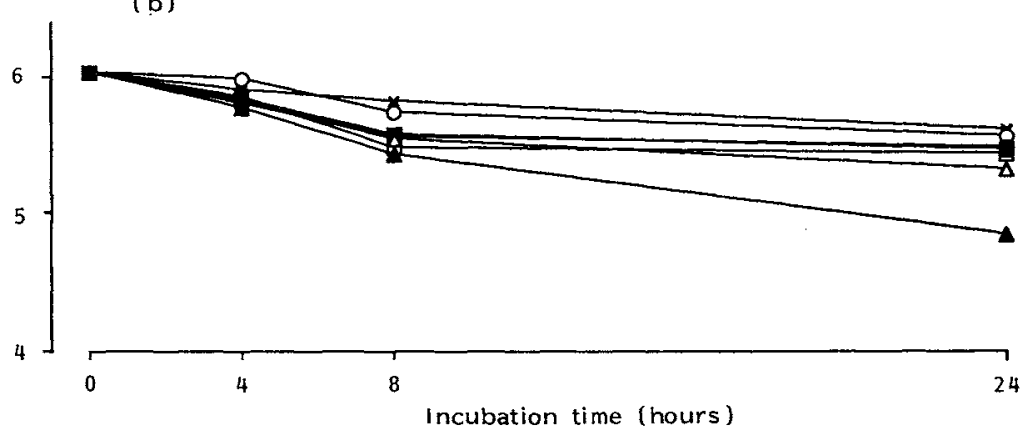

Therapeutic efficacy of AbA was compared with that of amphotericin B and fluconazole using the murine systemic candidiasis model. The study was performed with different regimens, dosings and routes of administration. As shown in Table 2, amphotericin B prolonged the survival days of mice at a wide range of dosages and was effective at one fourth or one eighth of the doses of fluconazole and $\mathrm{AbA}$. On the other hand, AbA and fluconazole protected mice from death more effectively than amphotericin $\mathrm{B}$. In the treatment starting on day-5, when mice were infected in their systemic organs including kidneys and were dying, AbA showed a better efficacy than fluconazole by sc and high dose po administration. $\mathrm{AbA}$ showed low toxicity; the $\mathrm{LD}_{50}$ values in mice were 231 , about $1,000,>1,000$ or $>1,000 \mathrm{mg} / \mathrm{kg}$ when given by iv, ip, sc or po route, respectively.

When mice with candidiasis were treated with AbA, mycological cure was achieved in the kidneys of all mice during the days treated, and a few days after the treatment (Table 3 ). This was probably due to 
Table 2. Antifungal activity against murine candidiasis of aureobasidin A (AbA), amphotericin B and fluconazole in the treatment of day- 0 to -5 or day- 5 to -9 .

\begin{tabular}{|c|c|c|c|c|c|c|}
\hline \multirow{2}{*}{ Drugs } & \multirow{2}{*}{ Route } & \multirow{2}{*}{$\begin{array}{c}\text { Dose } \\
(\mathrm{mg} / \mathrm{kg})\end{array}$} & \multicolumn{2}{|c|}{ Day-0 to -5} & \multicolumn{2}{|c|}{ Day-5 to -9} \\
\hline & & & $\mathrm{MSD} \pm \mathrm{SD}^{\mathrm{a}}$ & Survivors/total ${ }^{\mathrm{b}}$ & $\mathrm{MSD} \pm \mathrm{SD}$ & Survivors/total ${ }^{\mathfrak{c}}$ \\
\hline None & & & $5.9 \pm 1.6$ & $0 / 10$ & $11.2 \pm 5.7$ & $0 / 10$ \\
\hline \multirow[t]{8}{*}{$\mathrm{AbA}$} & $\mathrm{sc}$ & 2.5 & $15.8 \pm 3.6$ & $0 / 5$ & $8.6 \pm 2.4$ & $0 / 5$ \\
\hline & & 5 & $21.2 \pm 7.4$ & $1 / 5$ & $24.4 \pm 13.2$ & $0 / 5$ \\
\hline & & 10 & $29.8 \pm 1.8$ & $3 / 5$ & $35.8 \pm 13.1$ & $1 / 5$ \\
\hline & & 20 & $n t^{d}$ & & $32.8 \pm 16.0$ & $1 / 5$ \\
\hline & po & 10 & $18.4 \pm 9.0$ & $0 / 5$ & $8.2 \pm 1.1$ & $0 / 5$ \\
\hline & & 20 & $26.0 \pm 6.9$ & $1 / 5$ & $15.4 \pm 8.0$ & $0 / 5$ \\
\hline & & 40 & $23.2 \pm 8.1$ & $2 / 5$ & $36.4 \pm 10.1$ & $1 / 5$ \\
\hline & & 80 & nt & & $42.2 \pm 10.7$ & $3 / 5$ \\
\hline \multirow[t]{10}{*}{ Fluconazole } & $\mathrm{sc}$ & 0.63 & $12.4 \pm 4.3$ & $0 / 5$ & $\overline{\mathrm{nt}}$ & \\
\hline & & 2.5 & $18.8 \pm 7.7$ & $0 / 5$ & $\mathrm{nt}$ & \\
\hline & & 10 & $25.0 \pm 4.4$ & $0 / 5$ & $19.6 \pm 9.9$ & $0 / 5$ \\
\hline & & 20 & $\mathrm{nt}$ & & $11.4 \pm 4.8$ & $0 / 5$ \\
\hline & & 40 & $19.4 \pm 8.3$ & $0 / 5$ & $16.2 \pm 4.9$ & $0 / 5$ \\
\hline & po & 2.5 & $16.4 \pm 5.3$ & $0 / 5$ & nt & \\
\hline & & 10 & $20.4 \pm 9.7$ & $2 / 5$ & $24.4 \pm 19.8$ & $0 / 5$ \\
\hline & & 20 & $\mathrm{nt}$ & & $21.0 \pm 17.7$ & $1 / 5$ \\
\hline & & 40 & $24.0 \pm 9.6$ & $3 / 5$ & $34.0 \pm 11.6$ & $1 / 5$ \\
\hline & & 80 & $\overline{n t}$ & & $14.0 \pm 6.2$ & $0 / 5$ \\
\hline \multirow[t]{5}{*}{ Amphotericin B } & $\mathrm{sc}$ & 0.16 & $11.2 \pm 1.9$ & $0 / 5$ & $\mathrm{nt}$ & \\
\hline & & 0.63 & $16.4 \pm 8.2$ & $1 / 5$ & $22.4 \pm 17.1$ & $1 / 5$ \\
\hline & & 1.25 & nt & & $26.6 \pm 11.9$ & $0 / 5$ \\
\hline & & 2.5 & $16.6 \pm 14.5$ & $2 / 5$ & $24.2 \pm 16.3$ & $1 / 5$ \\
\hline & & 5 & $\overline{n t}$ & . & $27.8 \pm 16.0$ & $1 / 5$ \\
\hline
\end{tabular}

Drugs were given once daily from day- 0 to 5 or day- 5 to -9 .

a Median survival days \pm standard deviation.

b Number of mice survived among total mice on day-31.

c Number of mice survived among total mice on day-50 after infection.

d nt: not tested.

Table 3. Eradication of C. albicans cells from mice kidneys by treatment with aureobasidin A (AbA), fluconazole or amphotericin $\mathrm{B}$.

\begin{tabular}{|c|c|c|c|c|c|c|}
\hline \multirow{4}{*}{$\begin{array}{c}\text { Days } \\
\text { after } \\
\text { infection }\end{array}$} & \multicolumn{6}{|c|}{ No. of mice mycologically cured/total mice infected } \\
\hline & \multicolumn{6}{|c|}{ Drugs, dose, dosing schedule ${ }^{\mathrm{a}}$ and route } \\
\hline & \multirow[b]{2}{*}{ Vehicle } & \multicolumn{2}{|c|}{$\mathrm{AbA}$} & \multicolumn{2}{|c|}{ Fluconazole } & \multirow{2}{*}{$\begin{array}{c}\text { Amphotericin B } \\
5 \mathrm{mg} / \mathrm{kg} \\
\mathrm{sc} \mathrm{d} 3-9\end{array}$} \\
\hline & & $\begin{array}{c}20 \mathrm{mg} / \mathrm{kg} \\
\text { po d0-6 }\end{array}$ & $\begin{array}{c}40 \mathrm{mg} / \mathrm{kg} \\
\text { po d3-9 }\end{array}$ & $\begin{array}{c}20 \mathrm{mg} / \mathrm{kg} \\
\text { po d0-6 }\end{array}$ & $\begin{array}{c}40 \mathrm{mg} / \mathrm{kg} \\
\text { po } \mathrm{d} 3-9\end{array}$ & \\
\hline 0 & $0 / 5$ & & & & & \\
\hline 4 & $0 / 3$ & $3 / 3$ & $0 / 3$ & $0 / 3$ & $0 / 3$ & $1 / 3$ \\
\hline 7 & $0 / 3$ & $3 / 3$ & $3 / 3$ & $2 / 3$ & $0 / 3$ & $0 / 3$ \\
\hline 10 & $0 / 3$ & $2 / 3$ & $2 / 3$ & $0 / 3$ & $0 / 3$ & $1 / 3$ \\
\hline 14 & Dead & $1 / 5$ & $1 / 5$ & $0 / 5$ & $0 / 5$ & $3 / 5$ \\
\hline 21 & & $0 / 3$ & $0 / 3$ & $0 / 3$ & $0 / 3$ & $2 / 3$ \\
\hline
\end{tabular}

a Dosing schedule: d0 -6 , once daily from day -0 to -6 ; $\mathrm{d} 3-9$, once daily from day- 3 to -9 . 
the direct fungicidal action of AbA. When treatment with AbA was stopped, some mice regained infection, which may be due to the regrowth of cells not-killed by AbA. Mice treated by fluconazole were tentatively cured mycologically in the treatment on day- 0 and continued through day- 6 , but were rarely cured in the treatment starting on day-3. This observation can be ascribed to the fungistatic action of fluconazole. ${ }^{15}$ ) Mice treated by amphotericin B seemed to be gradually cured mycologically after the treatment was stopped. This effect was probably due to the immuno-potentiation activity of the polyene antibiotic. ${ }^{16)}$

In summary, $\mathrm{AbA}$ is a highly active, broad spectrum antifungal antibiotic with fungicidal action. AbA shows low toxicity and good efficacy against murine candidiasis when given orally as well as subcutaneously. AbA also prolongs survival days of infected mice by oral treatment, even when the treatment was started after completion of infection. Therefore AbA may be clinically useful for the treatment of fungal infections.

\section{References}

1) SAAG, M.S. \& W. E. DiSmukes: Azole antifungal agents: Emphasis on new triazoles. Antimicrob. Agents Chemother. 32: $1 \sim 8,1988$

2) Takesako, K.; H. Kuroda, I. Kato, T. Hiratani, K. Uchida \& H. Yamaguchi: Aureobasidins, a new family of antifungal antibiotics: Isolation, structure, and biological properties. In Recent Progress in Antifungal Chemotherapy. Ed., H. YamaGuchi et al., pp. $501 \sim 503$, Marcel Dekker, Inc., New York, 1992

3) Takesako, K.; K. IkaI, F. Haruna, M. Endo, K. Shimanaka, E. Sono, T. Nakamura, I. Kato \& H. Yamaguchi: Aureobasidins, new antifungal antibiotics: Taxonomy, fermentation, isolation and properties. J. Antibiotics 44 : $919 \sim 924,1991$

4) IKai, K.; K. Takesako, K. Shiomi, M. Moriguchi, Y. Umeda, J. Yamamoto, I. Kato \& H. Naganawa: Structure of aureobasidin A. J. Antibiotics 44: $925 \sim 933,1991$

5) HaROLD, F. M.: Antimicrobial agents and membrane function. Advances in Microbial Physiology 4: 45 104, 1970

6) Segre, A.; R. C. Bachmann, A. Ballio, F. Bossa, I. Grgurina, N. S. Iacobellis, G. Marino, P. Pucci, M. Simmaco \& J. Y., TAKEMOTO: The structure of syringomycins $\mathrm{A}_{1}$, E and G. FEBS Lett. 255: $27 \sim 31,1989$

7) Takemoto, J. Y.; L. Zhang, N. Taguchi, T. Tachikawa \& T. Miyakawa: Mechanism of action of the phytotoxin syringomycin: a resistant mutant of Saccharomyces cerevisiae reveals an involvement of $\mathrm{Ca}^{2+}$ transport. J. General Microbiol. 137: 653 659, 1991

8) MoOn, S.; J. L. Chen, R. E. MOORE \& G. M. PATterson: Calophycin, a fungicidal cyclic decapeptide from the terrestrial blue-green alga Calothrix fusca. J. Org. Chem. 57: 1097 1103, 1992

9) Mizuno, K.; A. Yagi, S. Sator, M. Takada, M. Hayashi, K. Asano \& T. Matsuda: Studies on aculeacin. I. Isolation and characterization of aculeacin A. J. Antibiotics 30: 297 302, 1977

10) Gordee, R. S.; D. J. Zeckner, L. F. Ellis, A. L. Thakkar \& L. C. Howard: In vitro and in vivo anti-Candida activity and toxicology of LY 121019. J. Antibiotics 37: 1054 1065, 1984

11) Mizoguchi, J.; T. Saito, K. Mizuno \& K. Hayano: On the mode of action of a new antifungal antibiotic, aculeacin A: Inhibition of cell wall synthesis in Saccharomyces cerevisiae. J. Antibiotics 30: 308 313, 1977

12) Yamaguchi, H.; T. Hiratani, K. Iwata \& Y. Yamamoto: Studies on the mechanism of antifungal action of aculeacin A. J. Antibiotics 35: 210 219, 1982

13) GUNJI, S.; K. ARIMA \& T. BEPPU: Screening of antifungal antibiotics according to activities inducing morphological abnormalities. Agric. Biol. Chem. 47: $2061 \sim 2069,1983$

14) Boeck, L. D.; D. S. Fukuda, B. J. Aввотt \& M. Debono: Deacylation of echinocandin B by Actinoplanes utahensis. J. Antibiotics 42: $382 \sim 388,1989$

15) Odds, F. C.; S. L. Chensman \& A. B. Aввотt: Antifungal effects of fluconazole (UK 49858), a new triazole antifungal, in vitro. J. Antimicrob. Chemother. 18: 473 478, 1986

16) Vecchiarelli, A.; G. Verducci, S. Perito, P. Puccetti, P. Marconi \& F. Bistoni: Involvement of host macrophages in the immunoadjuvant activity of amphotericin B in a mouse fungal infection model. J. Antibiotics 39: $846 \sim 855,1986$ 